\title{
Au-delà du TARMED - des polars nés au fond de cabinets médicaux suisses
}

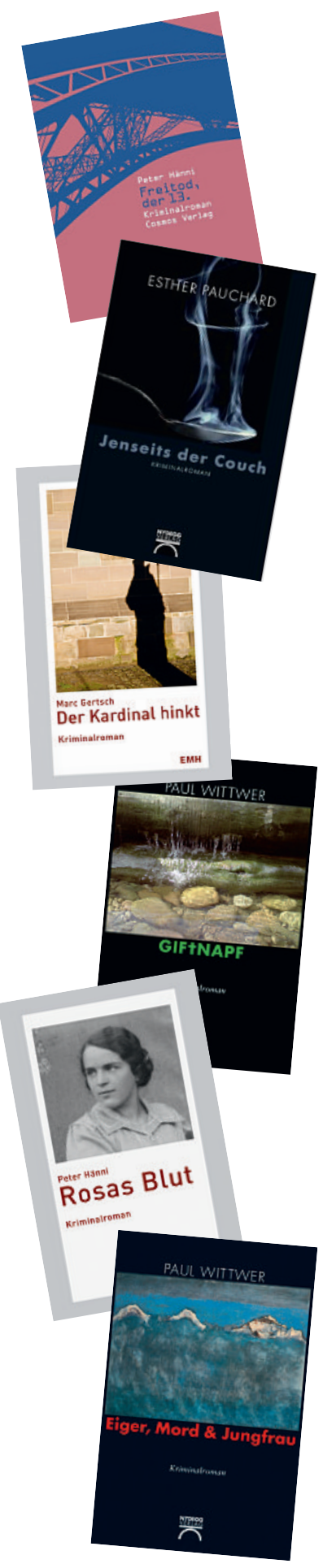

* Die Literaturangaben finden sich im Internet unter www.saez.ch $\rightarrow$ Aktuelle Nummer oder $\rightarrow$ Archiv $\rightarrow 2011 \rightarrow 8$.
Il est à peine exagéré de dire que la tradition du «roman policier bernois» a vu le jour à la fin du XIX ${ }^{\mathrm{e}}$ siècle. C'est en effet à cette époque que Sherlock Holmes, le père spirituel de tous les détectives de la littérature, a disparu dans les eaux tumultueuses des Chutes du Reichenbach dans le canton de Berne, à la suite d'une lutte acharnée avec son ennemi diabolique James Moriarty. Eu égard aux vives protestations de ses lecteurs, son créateur l'a finalement fait revivre quelques années plus tard, mais les Chutes du Reichenbach sont désormais indissociables du mythe du célèbre détective.

Sir Arthur Conan Doyle, l'inventeur du personnage de Sherlock Holmes, n'a pu vivre de son art qu'à partir de 1890. Auparavant, il dirigea pendant huit ans un cabinet médical à Portsmouth. Sans aller jusqu'à prétendre que son esprit a dû s'en retourner aux Chutes du Reichenbach, d'où il a inspiré des collègues médecins alentour, l'accumulation de romans policiers de médecins parus ces dernières années dans ce pays est tout de même étonnante et remarquable. Il n'est guère surprenant que la femme médecin auteur de romans policiers et ses trois collègues masculins soient originaires du canton de Berne, eu égard à la grande tradition bernoise dans ce domaine: l'inspecteur Studer et le commissaire Bärlach, deux enquêteurs ayant acquis une célébrité mondiale littéraire, ont tous deux résolu leurs affaires dans la ville de l'ours.

L'histoire de succès bernoise commence en pleine journée, par un cadavre échoué sur une plage de la Côte d'Azur, qui bouleverse l'existence du Dr Franco Weber et contraint ce jeune médecin-chef adjoint de la clinique de chirurgie cardio-vasculaire et transplantatoire de l'Hôpital de l'Ile bernois à jouer les détectives malgré lui. Le médecin généraliste d'Emmental Paul Wittwer a connu un vif succès en 2004 avec son premier roman «Eiger, Mord und Jungfrau», qui s'est hissé jusqu'à la troisième place dans le classement suisse des parutions et s'est maintenu dans les Top Ten pendant 26 semaines. Quatre ans plus tard, il réitérait son succès avec «Giftnapf». Le héros est cette fois-ci un jeune médecin amoureux de la vie du nom de Ben Sutter, avec une queue de cheval blonde et une barbe de trois jours.

Peter Hänni, Bernois lui aussi, établi comme otorhino-laryngologiste à Soleure, a fait ses débuts la même année, en 2008, avec "Rosas Blut», une saga familiale habilement construite. A l'instar de son collège Franco Weber, son «héros» du nom de Luca Clemente, est chirurgien à Berne, mais a des racines italiennes, ce qui dans son cas joue un rôle détermi- nant, dans tous les sens du terme. Entre-temps, Peter Hänni fait lui aussi partie des récidivistes: «Samenspende», une histoire d'empoisonnement avec plusieurs niveaux narratifs, louée par la critique pour son intrigue raffinée et la réflexion sur des questions éthiques délicates, est parue en 2009.

Marc Gertsch a prouvé l'an dernier que les écrits des médecins bernois ne se cantonnaient pas à leur région d'origine. Ce professeur émérite de cardiologie, qui s'était déjà fait un nom comme auteur d'ouvrages spécialisés (notamment «The ECG A Two-Step Approach to Diagnosis»), a élargi son répertoire de façon convaincante au roman policier. L'intrigue de «Der Kardinal hinkt» ne se situe pas à Berne, mais en Italie et le Questore Angelo Marconi, qui pour une fois n'est pas médecin mais un officier de police, doit faire preuve de tout son talent pour résoudre cette histoire complexe de mafieux, dont les ramifications conduisent jusqu'au Vatican.

Depuis peu, une femme apporte un vent de fraîcheur à ce domaine jusqu'à présent masculin des romans policiers suisses écrits par des médecins: Esther Pauchard, spécialiste en psychiatrie et psychothérapie à Berthoud, a décidé d'agir au-delà du divan («Jenseits der Couch»), une excellente décision pour les amateurs de polars. Sa Kassandra «Ka» Bergen bouscule un univers masculin fatigué et tient la dragée haute au méchant (un homme)... (voir la critique de son livre à la page 297 de la présente édition).

La multiplication des romans policiers suisses de médecins au cours des dernières années peut être le fruit du hasard, ce qui n'est, en revanche, pas le cas du phénomène des médecins écrivant des romans policiers. Dans l'entretien, les auteurs Paul Widmer, Peter Hänni et Marc Gertsch $[1,2]$ relèvent des parallèles entre leur métier d'origine et la méthodologie d'un détective. Esther Pauchard s'étonne même «que tous les médecins n'écrivent pas, du moins les psychiatres». Il y a donc une affinité naturelle qui porte ses fruits si les talents littéraires sont au rendez-vous, dans le meilleur des cas des talents qui réchauffent à la fois le cœur et donnent des frissons dans le dos.

Quoi qu'il en soit, les disciples suisses de Sir Arthur Conan Doyle et leur collègue semblent encore avoir d'autres cordes littéraires à leur arc - il existe un deuxième manuscrit achevé d'Esther Pauchard et le troisième ouvrage de Peter Hänni «Freitod, der 13.» sortira en librairie en mars. Autant de perspectives réjouissantes pour les amateurs de polars de qualité...

Bruno Kesseli 


\section{Références}

1 Kesseli B. Zwischen Achterbahn und Spiegellabyrinth. Bulletin des médecins suisses. 2009;90(38): 1481-4.

2 Lüthi D. Von Kardinalem und Kardialem. Bulletin des médecins suisses. 2010;91(50):2016-8.

3 Kammermann M. Die dunklen Ansichten einer Psychiaterin. Berner Zeitung du 28.10.2010; www.bernerzeitung.ch/region/emmental/ Die-dunklen-Ansichten-einer-Psychiaterin/story/ $29984090 z$ 